\title{
Impact of PVC mixtures of the Electrical Conduit on the Physical Properties
}

\author{
AbdelHamid M.S. Esmail ${ }^{*}$ \\ 1 Jubail Technical Institute, Collage and Institute Sector, Royal Commission for Jubail E Yanbu, KSA \\ * Corresponding author: AbdelHamid M.S. Esmail (saeed_a@jti.edu.sa).
}

Article history: Received 27 November 2019, Received in revised form 10 January 2020, Accepted 14 January 2021

\begin{abstract}
The use of PVC mixtures in the manufacturing of electrical conduit has been employed for a long time along with other materials. In this study, the impact of changing the ratio of the components of the PVC mixtures on the physical properties of the electrical conduit was investigated. The emphasis was placed on three properties: Density, Tensile Strength and Soft Point. The application of the electrical conduit controls the types of materials and their percentages. Physical properties of the PVC products are the most important factors that help to choose compared with other materials. These properties change with the change of the chemical components of the PVC mixture. The study discussed how to enhance and improve these properties by controlling the proportions of some substances in the PVC mixtures. This article aims to demonstrate the strong relationship between PVC polymer, calcium and stabilizers and the physical properties of the electrical conduit. The focus concentrated on three components in the mixture and three physical properties. Random samples were taken to calculate the average percentages of the components in the mixtures. Various tools and several statistical methods were used such as correlation coefficients and scatter charts to prove the relationship between the ratios of the materials and the respective properties. The correlation coefficients between the PVC polymer, stabilizers, calcium, and the density, tensile strength, vicat soft points were $(0.92$, $0.83,0.82)$ respectively. Decreasing the PVC polymer by $(17.1 \%)$ has caused an increase in the density of the conduit by $(2 \%)$. Finally, the physical properties of PVC mixtures could be improved by changing component ratios to reach the optimized mixture for the specific application, taking into account other competitive issues such as the final price of the product, environmental impact, and other issues.
\end{abstract}

Keywords: Density, Tensile Strength, vicat soft point, PVC polymer, Calcium, Stabilizer

\section{INTRODUCTION}

The electrical conduit is a pipe used to ensure the protection of electrical cables and wires in construction. Sometimes they made of plastic, metal or other materials. The main goal of using the conduit is for safety reasons, electrical wiring has to be shielded and grounded, which is achieved by running it, where necessary, through electrical conduits [1]. The conduits used for different applications such as power distribution, branch lighting, branch power, and conduit for fire alarm or data cabling [2]. Uses of electrical conduits fall under specific laws and regulations that vary from country to country. The goal of these legislations and standards is to control the specifications and the manufacturing of the conduit industry. These standards updated from time to time as needed. Example of that, the concealed wiring protection, in the old standard, it was required to adopt the rigid plastic tube with fire retardant treatment, while in the new standard, it is revised to flexible rigid plastic tube above B1 grade [3]. Some originations work on these standards such as National Electrical Code, the Canadian Electrical Code and the National Electrical Manufacturers Association, which was updated Standard for Electrical Intermediate 
Metal Conduit Raceways, as an example [7] [4]. The primary engine of these updates is the safety issue, if safety issues are ignored, incidents such as Concrete Cutting Catastrophe could occur. When "five parallel electrical conduits running perpendicular to the concrete cut. Four of the conduits were laid directly on the soil and were encased in concrete, while the fifth was running beneath the soil. All of the conduits were severed by the saw. Later excavation revealed that these were the only conduits traveling beneath the extruder footprint" [5]. Therefore, standards organizations reveal and clarify updated standards so that they are not misunderstood for example, when electrical conductors are placed in conduits located in sunlight, the interiors of those conduits can reach quite high temperatures [6]. This leads to talk about the physical properties of these conduits and their tolerance to operating conditions and how to improve them. These conduits are used by specialized technicians. In the case of non-specialists work in the installation of these electrical conduits an electrical accident could happen, for example, hearing the sound and seeing the bright flash of an electrical arc can create the false impression that someone had experienced an electrical shock [8]. The method of inserting wires and cables into electrical conduits ensures that they are protected from erosion and chemical agents and that wires are easily changed when needed. There are several ways and techniques to work on electrical conduits, whether underground or outside [9]. What makes it necessary to the skillful technician to know the physical properties of electrical conduits and their types.

Electrical conduits vary depending on their usage and their physical, chemical and mechanical properties. The common uses of PVC conduit are concealed within walls, floors, or ceilings, directly buried or embedded in concrete in buildings of any height [11]. Cost also forms another dimension in the selection of the electrical conduits, including installation and other direct and indirect costs. The global electrical conduit fittings market is set to exhibit a CAGR of $6.7 \%$ during the forecast period from 2018 to 2026.
Electrical conduit systems are the most common type of wiring installations worldwide [10]. However, for underground cables which are laid in conduits, it can become much more difficult to locate cable faults. It is important to fully utilize the technics of locating underground cable faults inside conduits [14]. Generally, the conduits vary based on their uses such as:

- Electrical conduits, public pipes

- High resistance, electrical conduits

- Conveyor electrical conduits

- Corrugated electrical conduits

- Cold-folding electric conduits and high impact

- Electrical conduits for internal uses

- Electrical conduits for external uses

- Electrical drainage conduits

PVC conduits have many advantages including the low cost and lightweight of PVC compared with other materials. PVC conduits also have other advantages such as fire resistance, acid or base chemical resistance, rust resistance compared to metal types, easy installation, and shape compared to metal and attractive appearance especially in decorating. There are many types of PVC conduits, including but not limited to Type B PVC Conduit, Type B PVC Tubing and Type A Conduit [13]. These types like many countries, allow underground cables to be laid inside PVC conduits. Pinpointing cable faults would be much easier when the cables are buried underground directly [14].

Next, the components of the PVC mixture will be explained, Polyvinyl chloride (PVC) is one of the major synthetic resin and is widely used in the building and other industries. Additives are often added in the production of plastics to improve the properties of plastics or lower the cost [15]. Also from the features of PVC, it's varying in molecular weight and distribution, homo-, co-, and terpolymers, particle size and distribution, morphology, crystallinity, etc. And the ability of PVC to be formulated with a multitude of additives, unmatched by any other plastic [16]. Engineered thermoplastic materials, as well as thermosetting materials, are used in specialty 
pipe, tubing, and fittings applications. There are several commonly used thermoplastic materials for particular piping and fittings applications, the main two materials are polyvinyl chloride PVC and high-density polyethylene, which make up more than $90 \%$ of the total market [17]. The calcium fillers in the PVC mixture worked to enhances the material stiffness (the elastic modulus), whereas it reduces tensile strength and elongation at break. In terms of flexural properties, flexural strength and flexural modulus were found to be enhanced with the incorporation of fillers [18]. In the other hand, the impact of the calcium particle size was studied in rigid PVC formulations. The study of the particle size affect in foam formulations proved that smaller particle size enables the efficient fusion of the compound [19]. In order to inhibit the thermal degradation of the polymer, traditional stabilizers have been commonly used in the PVC mixtures [20]. The processing of raw PVC using heat and pressure. This condition results in severe polymer degradation and discoloration due to the production of hydrogen chloride. Stabilizers are added to prevent the elimination of hydrogen chloride from PVC and subsequent decomposition [21]. Several types of special polymers will furnish the necessary marginal compatibility with PVC to provide the shock-absorbing mechanism required to enhance the impact strength of the PVC product and also to function as impact modifiers. If an optimum choice of all other formulation components is made without adequate consideration for proper lubricant balance, chances for successful extrusion are minimal. The plasticizers in the PVC mixtures generally work to decrease surface resistivity of nonblack compounds [16].

The physical properties of PVC conduits help to choose the right conduit according to the application. The types of physical properties are assigned based on the market requirements and the customer of the plant and they controlled as per the Standards (ISO 1183, ISO 527, ISO 179 and ISO 306). One of the most important of these physical properties is density, which defined as the ratio of the mass of a sample to its volume at the temperature. The density tests based on the ISO 1183 which specifies three methods for the determination of the density of non-cellular plastics in the form of void-free moulded or extruded objects, as well as powders, flakes and granules [22]. The next property is the Tensile Strength which tests under the ISO 527 to specify the general principles for determining the tensile properties of plastics and plastic composites under defined conditions [23]. The ISO 179 specifies a method for determining the Charpy impact strength of plastics under defined conditions [24]. While ISO 306 specifies four methods for the determination of the Vicat softening temperature (VST) of thermoplastic materials [25]. Finally, the Elongation at Break is also tested via the early mentioned standard ISO 527 [23].

From the abovementioned physical properties, we notice that the physical properties vary according to the proportions of the materials in the PVC mixture. The need to reach the optimal physical properties of products is achieved by changing the proportions of materials, and according to the application to be used. This study tried to focus on understanding the effects resulting from the change of three raw chemicals on three physical properties throughout some statistical tools. To solve this problem, many experiments were carried out on PVC mixtures to manufacturing conduits by changing the proportions of the raw chemicals and recorded them. Several methods were used to determine the nature of the assumed relationships between chemicals and physical properties.

\section{RESEARCH OBJECTIVES}

The objective of this study was to understand the physical properties impact and change by changing the proportions of chemicals in PVC mixture, in addition, to enhance and develop the physical properties of PVC conduit products. The study also aimed to reveal the nature of the relationship between the physical properties and chemicals in the PVC mixture for the electrical conduits. 


\section{MATERIALS AND METHODS}

\section{A. Introduction}

This study was conducted in the National Plastic Company using the company's equipment to extract the results of the performed experiments. The periods of the study were when I had worked in the company. My goal was to develop an optimal mixture to produce materials with high competitive specifications to fulfill the market customers' needs.

Various materials have been used in the experiments to make the electrical conduits such as PVC (Polyvinyl Chloride, PVC Resin K67 SG), Calcium (Calcium Carbonate, particle size 1.2\%, brightness 95\%), Stabilizer (MC 4769 RR, specific gravity 1.04), Modifier which is Acryloid K-120N powder of methyl methacrylate and ethyl acrylate, Lubricant (mix of calcium stearate and paraffin wax) and Plasticizers and Color.

The experimental work was based on factory procedures which conduct numerous preliminary trial and error experiments, with the help of the extrusion technicians, the simple model of the design of experiment were assigned. The processing variables, the mixture components were identified as it appears in table 1.

The designed tool that assists the collection of data for the purpose of analysis was the factory trial form which contains the raw materials data in two forms; wt. per kilogram and the percentage.

Data were collected on the required specifications, and accordingly, twenty-five experiments were made by making mixtures for each trial (m1, m2, m3, m4, and $\mathrm{m} 5)$, the average of five experiments was taken for each category so that the mixtures were processed to produce the product. Follow by the tests in the laboratory to grantee the required results as in table 2.

The study was made of PVC polymer trial mixtures and the goal of these experiments was to obtain the optimal possible physical properties at specific and semi-stable operating conditions, knowing that, this study did not address the detailed operating conditions and the method of manufacturing of PVC conduits. The results of the experiments are summarized in the following tables; table of the percentage of raw materials of the electrical conduit and table of the results of the technical tests of the physical properties of the PVC mixtures of the electrical conduit.

A combination of five PVC mixtures for five trial products was used. The focus was on three physical properties to be studied based on the highest values of the Correlation Coefficient as they appear in table 3 and the change in the composition of the input materials for each type of PVC mixture. These properties are:

- Density $\left(\mathrm{gm} / \mathrm{cm}^{3}\right)$

- Tensile Strength $\left(\mathrm{N} / \mathrm{mm}^{2}\right)$

- Vicat Soft Point $\left(\mathrm{C}^{\circ}\right)$

B. Correlation of change in the proportions of PVC mixtures on physical properties

The results of the mixtures were summarized with the contents of each trial product. For the sake of study their physical properties separately to determine the greatest affect of the materials in the mixture as illustrates in Table 1. These mixtures took into account the applications to be used for each area of the electrical conduits. As explained earlier in the introduction.

Thereafter, the physical properties of each mixture were tested, analyzed and studied. Five physical properties were selected to determine the impact of chemical ratios on the physical properties to know where are the affects? Whether an increase or decrease in the properties was happened according to the change in the ratios of the chemicals as appears in table 2 below.

\begin{tabular}{|c|c|c|c|c|c|}
\hline Trial & M1 (\%) & M2 (\%) & M3 (\%) & M4 (\%) & M5 (\%) \\
\hline PVC & 86 & 82 & 78 & 72 & 71 \\
\hline Calcium & 9 & 10 & 16 & 25 & 26 \\
\hline Stabilizer & 2 & 6 & 4 & 2 & 2 \\
\hline Modifier & 1 & 0 & 0 & 0 & 1 \\
\hline Lubricant & 1 & 0 & 1 & 0 & 1 \\
\hline Plasticizer & 0 & 1 & 0 & 0 & 0 \\
\hline Color & 2 & 0 & 2 & 1 & 0 \\
\hline Total & 100 & 100 & 100 & 100 & 100 \\
\hline
\end{tabular}

Table 1: Raw Materials Percentage of the PVC mixtures

\begin{tabular}{|c|l|c|c|c|c|c|}
\hline \multirow{2}{*}{ Reference } & \multirow{2}{*}{ Physical Property } & \multicolumn{5}{|c|}{ Trial } \\
\cline { 3 - 7 } & & M1 & M2 & M3 & M4 & M5 \\
\hline ISO 1183 & Density $\left(\mathrm{gm} / \mathrm{cm}^{3}\right)$ & 1.49 & 1.5 & 1.52 & 1.52 & 1.52 \\
\hline ISO 527 & Tensile Strength $\left(\mathrm{N} / \mathrm{mm}^{2}\right)$ & 46 & 41 & 42 & 43 & 46 \\
\hline ISO 179 & Izod Impact Strength (J/m) & 115 & 90 & 80 & 100 & 80 \\
\hline ISO 306 & Vicat Soft Point (C) & 85 & 83 & 82 & 81 & 82 \\
\hline ISO 527 & Elongation at Break (\%) & 120 & 135 & 110 & 110 & 105 \\
\hline
\end{tabular}

Table 2: Physical Properties of the PVC Mixtures

A preliminary study was conducted to clarify the relationship between the ratios of the 
substances in the mixtures and the physical properties by using the correlation coefficient of the two sets of the data to determine the relationship between them as appears in table 3 and by using the following equation:

$$
\operatorname{Correl}(x, y)=\frac{\sum(x-\bar{x})(y-\bar{y})}{\sqrt{\sum(x-\bar{x})^{2} \sum(y-\bar{y})^{2}}}
$$

Where $(\bar{x}, \bar{y})$ is the Average (Percentage of the materials) and Average (Physical properties). The relationship between the ratios of the materials and the physical properties prominently appears and they discussed with details as follows:

\begin{tabular}{cccccc}
\hline $\begin{array}{c}\text { Raw } \\
\text { Material }\end{array}$ & $\begin{array}{c}\text { Density } \\
\left(\mathbf{g m} / \mathbf{c m}^{3}\right)\end{array}$ & $\begin{array}{c}\text { Tensile Strength } \\
\left(\mathbf{N} / \mathbf{m m}^{2}\right)\end{array}$ & $\begin{array}{c}\text { Izod Impact } \\
\text { Stength } \\
(\mathbf{J} / \mathbf{m})\end{array}$ & $\begin{array}{c}\text { Vicat Soft } \\
\text { Point }\left(\mathbf{C}^{\circ}\right)\end{array}$ & $\begin{array}{c}\text { Elongation at } \\
\text { Break (\%) }\end{array}$ \\
\hline PVC & -0.92 & -0.06 & 0.58 & 0.90 & 0.73 \\
\hline Calcium & 0.85 & 0.21 & -0.42 & -0.82 & -0.77 \\
\hline Stabilizer & -0.23 & -0.83 & -0.31 & 0.08 & 0.76 \\
\hline Modifier & -0.39 & 0.95 & 0.36 & 0.61 & -0.22 \\
\hline Lubricant & -0.06 & 0.58 & -0.06 & 0.41 & -0.45 \\
\hline Plasticizer & -0.40 & -0.63 & -0.11 & 0.15 & 0.89 \\
\hline Color & -0.21 & 0.02 & 0.31 & 0.38 & -0.12 \\
\hline
\end{tabular}

Table 3: Correlation Coefficient of The properties vs. the raw materials

\section{Correlation of PVC ratios with Density}

From table 3, the correlation coefficient between the PVC ratio and the density was (92\%), which means there is a statistical relationship between the two variables. The scatter chart of the PVC polymer vs. density $\left(\mathrm{gm} / \mathrm{cm}^{3}\right)$ was drawn to illustrate the nature of the relationship between the two variables and to extract the general equation of a straight line as follows:

$$
y=-0.2078 x+1.6718
$$

Were $y=$ the density and $x=$ the PVC ratio.

\section{Correlation of Stabilizer ratios with Tensile Strength}

The correlation coefficient between the Stabilizer ratio and tensile strength was $(83 \%)$, which means there is a statistical relationship between the two variables as shown in table 3 . The scatter chart of the stabilizer vs. tensile strength $\left(\mathrm{N} / \mathrm{mm}^{2}\right)$ was drawn to illustrate the nature of the relationship between the two variables and to extract the general equation of a straight line as follows:

$$
y=-100.17 x+46.901
$$

Were $y=$ the tensile strength and $x=$ the stabilizer ratio

\section{E. Correlation of Calcium ratios with Vicat Soft Point}

From table 3, the correlation coefficient between the calcium ratio and vicat soft point was $(82 \%)$, which means there is a statistical relationship between the two variables. The scatter chart of the calcium vs. vicat soft point $\left(\mathrm{C}^{\circ}\right)$ was drawn to illustrate the nature of the relationship between the two variables and to extract the general equation of a straight line as follows:

$$
y=-15.668 x+85.261 \ldots \ldots
$$

Were $y=$ the vicat soft point

and $x=$ the calcium ratio

After confirming the relationship between the change of percentages of the material and the change in the physical properties through the correlation coefficient and above equations. The shapes of these changes were drawn, to clarify, whether this change is positive or negative throughout, making a graph of each change one material to one physical property to produce specific results as shown below.

\section{RESULTS}

From the test results of the physical properties for the trial products, it is clear that the density in the tested samples ranges from $\left(1.49 \mathrm{mg} / \mathrm{cm}^{3}\right)$ to $\left(1.52 \mathrm{mg} / \mathrm{cm}^{3}\right)$, corresponding to PVC ratios which are ranging from $(71.3 \%)$ to $(86 \%)$. The tensile strength ranges between $\left(41 \mathrm{~N} / \mathrm{mm}^{2}\right)$ and $\left(46 \mathrm{~N} / \mathrm{mm}^{2}\right)$, and the ratio of stabilizer in the mixes between $(1.8 \%)$ and $(6.2 \%)$. The ratios of the calcium in the mixture samples range between $(8.6 \%)$ and $(25.5 \%)$ and caused vicat soft point between $\left(81 \mathrm{C}^{\circ}\right)$ and $\left(85 \mathrm{C}^{\circ}\right)$.

\section{A. Impact of PVC change on density}

From figure 1, it appears that the increase of the PVC ratio in the mixture of manufacturing the electrical conduit, caused the density of the produced electrical conduit to be decreased. On this basis, this type can be used in an electrical conduit which intended for high impact. 


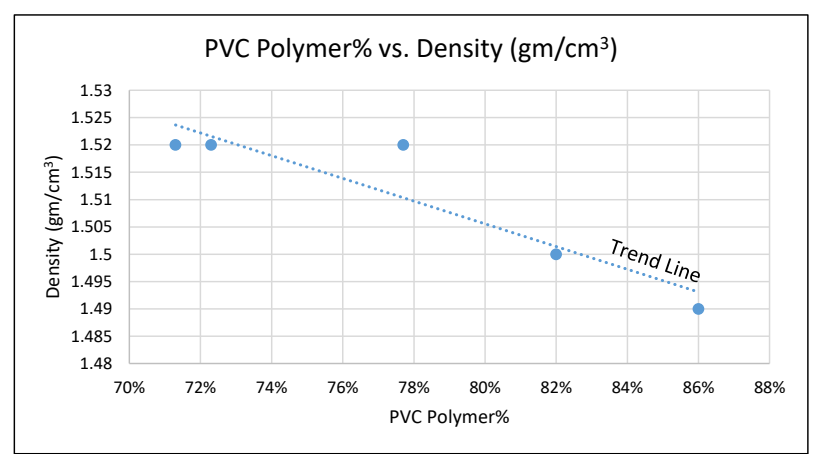

Figure 1: Scatter Chart of the PVC Polymer vs. Density

The relationship between PVC ratio and density was a negative relationship. Which mean by decreasing the percentage of PVC in the mixture from $(86 \%)$ to $(71.3 \%)$ the density has increased from $\left(1.49 \mathrm{mg} / \mathrm{cm}^{3}\right)$ to $\left(1.52 \mathrm{mg} / \mathrm{cm}^{3}\right)$, depending on the type of the required product and according to the use, as is illustrated in figure 2. The reason for this relationship is that the PVC naturally very brittle and its specific gravity around $1.4 \mathrm{gm} / \mathrm{m}^{3}$, which means by adding more PVC the specific gravity comes around $1.4 \mathrm{gm} / \mathrm{m}^{3}$.

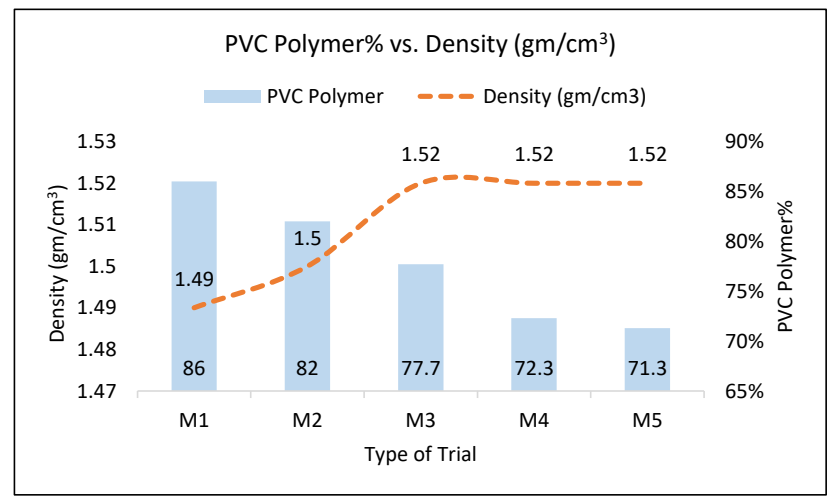

Figure 2: Impact of PVC change on Density

\section{B. Impact of stabilizer change on tensile strength}

The increase of the stabilizer ratio in the mixture of manufacturing the electrical conduit, caused the tensile strength of the produced electrical conduit to be decreased. On this basis, this type can be used in an electrical conduit which intended for the corrugated pipe with a small diameter. As shown in figure 3.

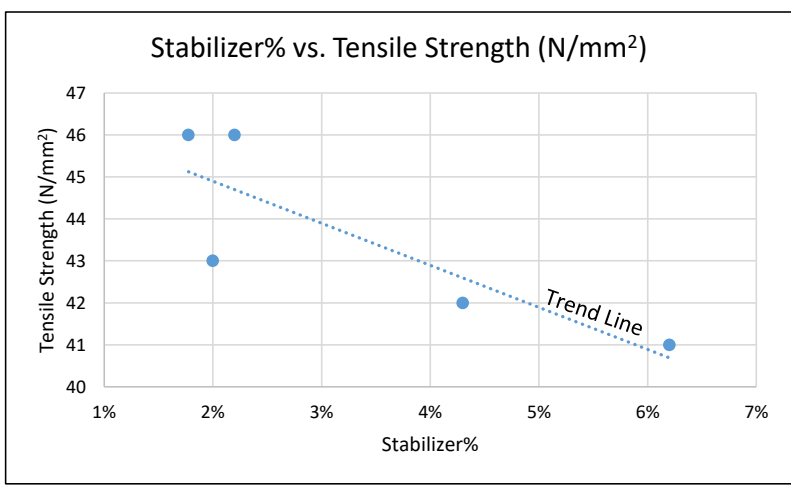

Figure 3: Scatter Chart of the Stabilizer vs. Tensile Strength

From figure 4, the relationship between the change of stabilizer and tensile strength was a negative relationship. Which means decreasing the percentage of stabilizer in the mixture from $(6.8 \%)$ to $(1.8 \%)$, the tensile strength would be increased from $\left(41 \mathrm{~N} / \mathrm{mm}_{2}\right)$ to $\left(46 \mathrm{~N} / \mathrm{mm}^{2}\right)$, depending on the type of the required product and according to the use. The reason for this relationship was that adding stabilizer normally to improve the thermal properties of the polymer and to prevent the elimination of hydrogen chloride from PVC, which increase the stiffness and degrease the tensile strength.

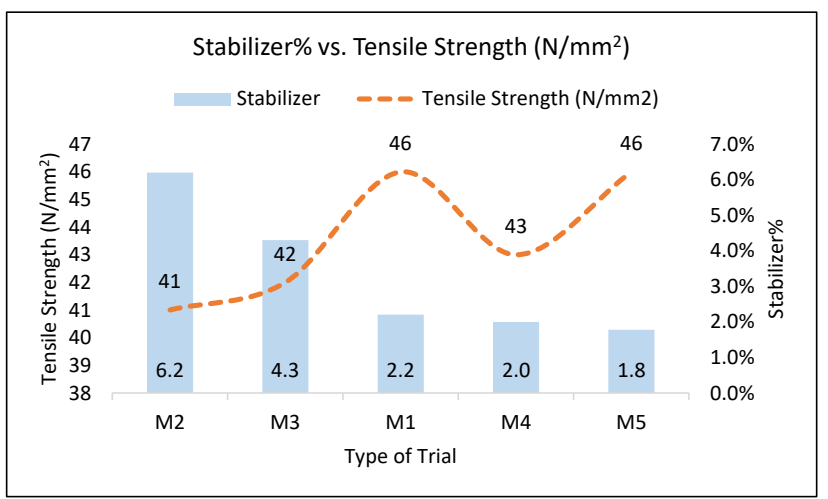

Figure 4: Impact of the Stabilizer on Tensile Strength

\section{Impact of calcium change on vicat soft point}

From figure 5, it appears that the increase of the calcium ratio in the mixture of manufacturing the electrical conduit, caused the vicat soft point of the produced electrical conduit to be decreased. On this basis, this type can be used in electrical conduit which intended for general pipes. 


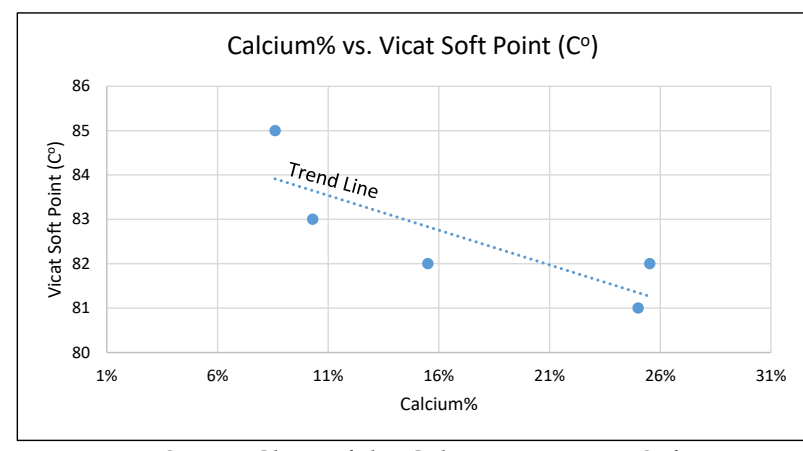

Figure 5: Scatter Chart of the Calcium vs. Viscat Soft Point

The relationship between calcium change and viscat soft point was a negative relationship. Which means, by increasing the percentage of calcium in the mixture from $(8.6 \%)$ to $(25.5 \%)$ the viscat soft point has decreased from $\left(85 \mathrm{C}^{\circ}\right)$ to $(81$ $\mathrm{C}^{\circ}$ ), depending on the type of the required product and according to the use, as is illustrates in figure 6 . The reason of this relationship is that the calcium enhances the material stiffness and disperse various ingredients into the PVC mixture and making the mixture flow more homogenous due to the particle sizes become smaller, which lead to low viscat soft point.

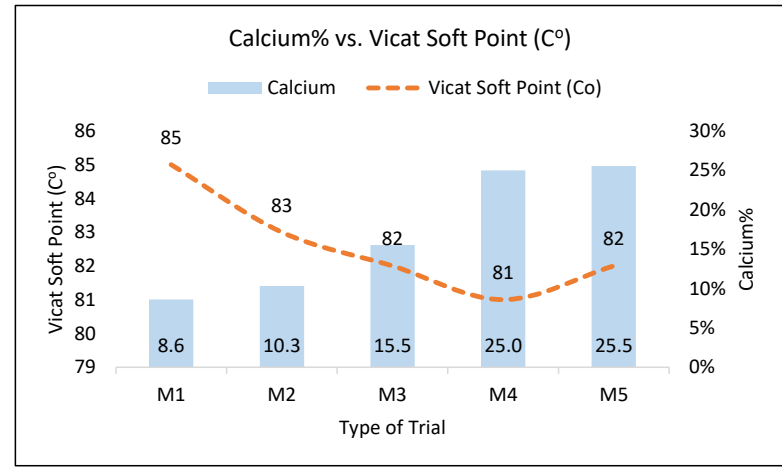

Figure 6: Impact of the Calcium change on Viscat Soft Point

\section{DISCUSSION}

From the previous results, it is clear that the proportions of the materials which form the electrical conduit significantly affect the physical properties (Density, Tensile Strength and Vicat Soft Point). The extracted equations (1, 2 and 3) could be used to obtain the required value of the physical properties.

Some of the previous studies have been also focusing on the physical properties such as the fabricate virgin polyvinyl chloride, and low-density polyethylene blended with their corresponding recycled material in different ratios of the virgin/recycled via injection molding and to evaluate their tensile strength, impact fracture, and hardness behavior [26]. Others make selective modification by ozonation for the surface of polyvinyl chloride (PVC) which was evaluated to separate PVC from the other plastics, with almost the same density as PVC by the froth flotation process [28]. While other studies used some of these physical properties to produce an oil with a low level of chlorine from a mixture of low-density polyethylene and polyvinyl chloride waste [27]. On the other side group of studies sought on the tensile strength such as the blends yielded tensile stress-strain curves very dependent on their composition [29]. The incorporation of PVC coated welded wire mesh slightly increases the tensile strength of concrete were studied also [30]. At the end the previous studies focus on the inclusion of ethylene dimethacrylate exhibited higher tensile strength for all filler loadings of PVC conductive composite films [12].

\section{CONCLUSION}

The outcome of this study that, the applications of electrical conduits determine the type of the required physical properties such as high vicat soft point which use for cold blending and high impact electrical conduits and the low vicat soft point for general electrical conduits. It is also possible to work deeply in other micro studies to give more explanation about each physical property and the opposite related materials. Taking into account that there are many different factors that can work individually or in combination were not address in this study. Throughout the abovementioned trial mixtures, the M4, M5 are preferred for the general pipe, general electrical conduit respectively. While M1, M2, and M3 are preferred for high resistance, small size diameter, and trucking electrical conduits respectively. Finally, the components of PVC mixtures and the importance of enhancing its physical properties were studied, due to the low cost of the PVC in the manufacturing of electrical conduit and its low impact on the environment in general. 


\section{REFERENCES}

[1] Wolff-Michael Roth. (2014). Rules of bending, bending the rules: the geometry of electrical conduit bending in college and workplace. Educational Studies in Mathematics, 86(2), 177.

[2] DelPico, W. J., \& R.S. Means Company. (2014). Electrical Estimating Methods (Vol. Fourth edition). Hoboken, New Jersey: RSMeans.

[3] Yao, H., Zhang, P., Zheng, Y., \& Liang, D. (2016). Introduction for Code for Design of Automatic Fire Alarm System. Procedia Engineering, 135, 67-71.

[4] NEMA Publishes Requirements for Steel Electrical Intermediate Metal Conduit (EIMC) for Use as a Raceway. (2019). ThomasNet News, N.PAG.

[5] Paris, A. dparis@andeng. ne. (2012). The Case of the Concrete Cutting Catastrophe. EC\&M Electrical Construction \& Maintenance, 111(2), 8-11.

[6] Effect of Rooftop Exposure in Direct Sunlight on Conduit Ambient Temperatures. (2008). IEEE Transactions on Industry Applications, Industry Applications, IEEE Transactions on, IEEE Trans. on Ind. Applicat, (6), 1872.

[7] Electrical process seal requirements in North American Electrical Codes. (2008). 2008 55th IEEE Petroleum and Chemical Industry Technical Conference, Petroleum and Chemical Industry Technical Conference, 2008. PCIC 2008. 55th IEEE, 1.

[8] Kroll, M. W., Ritter, M. B., Perkins, P. E., Shams, L., \& Andrews, C. J. (2019). Perceived Electrical Injury: Misleading Symptomology Due to Multisensory Stimuli. Journal of Emergency Medicine, 56(5), e71-e79.

[9] Chandler, D. (2019). Conduit Bending Tips. EC\&M Electrical Construction \& Maintenance, 118(6), C8-C12.

[10] Research and Markets. (3AD 2019). Global Electrical Conduit Fittings Market Study, 2019: Industry Size \& Share, Application Analysis, Regional Outlook, Growth Trends, Key Players, Competitive Strategies (2018-2026) - ResearchAndMarkets.com. Business Wire.

[11] Holt, M. (2019). Stumped by the Code? EC\&M Electrical Construction \& Maintenance, 118(8), 37.

[12] Yazid, M. I. M., Ghani, S. A., Osman, A. F., \& Din, S. H. M. (2018). Enhancement of Electrical Conductivity and Tensile Properties of Conductive Poly(vinyl Chloride)/Poly(ethylene Oxide)/Polyaniline Conductive Composite Films: Effect of Polyaniline Loading and Ethylene Dimethacrylate. Journal of Physical Science, 29(2), 1-12.

[13] Yoss, C. (2006). Guide to Nonmetallic Conduit Applications. Electrical Contracting Products, 9(3), 28-29.

[14] Cheung, G., Tian, Y., \& Neier, T. (2016). Technics of locating underground cable faults inside conduits. CMD 2016 International Conference on Condition Monitoring and Diagnosis, 619-622.

[15] Wang, Chongqing; Wang, Hui; Fu, Jiangang; Gu, Guohua. (2014). Effects of additives on PVC plastics surface and the natural flotability. In Colloids and Surfaces A: Physicochemical and Engineering Aspects.
[16] Grossman, Richard F. (2008). Handbook of Vinyl Formulating. Wiley Series on Plastics Engineering \& Technology. Edition: 2nd ed. Hoboken : Wiley-Interscience.

[17] By Walsh, Thomas. (2017). The Plastic Piping Industry in North America. In Applied Plastics Engineering Handbook Edition: Second Edition.

[18] Guermazi, Noamen; Haddar, Nader; Elleuch, Khaled; Ayedi, H. Ferid. (2016). Effect of filler addition and weathering conditions on the performance of $\mathrm{PVC} / \mathrm{CaCO} 3$ composites. Polymer Composites. Jul, Vol. 37 Issue 7, p2171-2183. 13p.

[19] Radovanović, R. R. R. r., Jašo, V., Pilić, B., \& Stoiljković, D. (2014). Effect of PVC plastisol composition and processing conditions on foam expansion and tear strength. Chemical Industry / Hemijska Industrija, 68(6), 701-707.

[20] ZHANG, W., DONG, D., WEI, Z., \& MA, Y. (2014). Synthesis of lanthanum ricinoleate and its effect on thermal stability and mechanical properties in PVC. Journal of Rare Earths, 32(11), 1089-1094.

[21] Altarazi, S. A., \& Allaf, R. M. (2017). Designing and analyzing a mixture experiment to optimize the mixing proportions of polyvinyl chloride composites. Journal of Applied Statistics, 44(8), 1441-1465.

[22] INTERNATIONAL STANDARD, (2004), Plastics - Methods for determining the density of non-cellular plastics, (ISO 1183-1:2004).

[23] INTERNATIONAL STANDARD, (2012), Plastics Determination of tensile properties, (ISO 527-1:2012).

[24] INTERNATIONAL STANDARD, (2010), Plastics Determination of Charpy impact properties, (ISO 179-1:2010).

[25] INTERNATIONAL STANDARD, (2004), Plastics Thermoplastic materials - Determination of Viscat softening temperature (VST), (ISO 306:2004).

[26] Marulanda, D., Perez, M., \& Correa, L. (n.d.). Influence of the percentage of recycled material on the mechanical properties of low-density polyethylene, polyethylene terephthalate, and polyvinyl chloride. JOURNAL OF ELASTOMERS AND PLASTICS, 46(4), 355-367.

[27] Park, K.-B., Oh, S.-J., Begum, G., \& Kim, J.-S. joosik@uos. ac. k. (2018). Production of clean oil with low levels of chlorine and olefins in a continuous two-stage pyrolysis of a mixture of waste low-density polyethylene and polyvinyl chloride. Energy, 157, 402-411.

[28] Okuda T, Kurose K, Nishijima W, Okada M. Separation of Polyvinyl Chloride from Plastic Mixture by Froth Flotation after Surface Modification with Ozone. Ozone: Science \& Engineering. 2007;29(5):373-377.

[29] Strapasson, R., Amico, S. C., Pereira, M. F. R., \& Sydenstricker, T. H. D. (2005). Tensile and impact behavior of polypropylene/low density polyethylene blends. Polymer Testing, 24(4), 468-473.

[30] Wijatmiko, I., Wibowo, A., \& Nainggolan, C. R. (2019). Characteristics of PVC Coated Welded Wire Mesh Fiber Reinforced Concrete. Civil Engineering Dimension, 21(1), 50-55. 